\title{
Avaliação do potencial de carbonatação de cales hidratadas em pasta
}

\author{
Evaluation the potential of carbonation \\ of hydrated limes paste
}

\author{
Marienne do Rocio de Mello Maron da $\operatorname{Costa}^{1}$, Ana Paula Gessi Pacheco ${ }^{2}$
}

\author{
${ }^{1}$ Departamento de Construção Civil - UFPR, Centro Politécnico, Curitiba, PR, Brasil \\ e-mail: mariennemaron@gmail.com \\ ${ }^{2}$ Aluna de graduação da UFPR - Brasil \\ e-mail: apgessi@gmail.com
}

\begin{abstract}
RESUMO
A cal hidratada é um aglomerante aéreo largamente utilizado na construção civil, utilizada principalmente em argamassas por melhorar seu comportamento reológico. Com as inovações tecnológicas, o uso da cal hidratada vem perdendo seu espaço em argamassas e vem sendo substituída por aditivos e adições minerais, que na maioria dos casos conferem características semelhantes no estado fresco das argamassas, mas desempenho reduzido no estado endurecido. Outro fator importante que contribui para a redução do seu emprego em argamassas, se refere ao reduzido ganho de resistência nas primeiras idades, devido à velocidade lenta de endurecimento; por se tratar de um aglomerante aéreo, a solidificação depende do contato com o anidrido carbônico do ar. O emprego de espessuras elevadas de argamassa de cal em revestimentos ajudou a reduzir seu emprego, pois torna a reação de carbonatação ainda mais lenta, comprometendo o cronograma da obra. Dentro deste contexto, este trabalho objetiva avaliar o potencial de carbonatação de cinco diferentes tipos de cales hidratadas encontradas no mercado paranaense. Para avaliação da carbonatação, foram feitas pastas de cal que ficaram acondicionadas tanto em ambiente de laboratório quanto em câmara de carbonatação com temperatura e umidade controladas. Tornou-se possível observar o avanço da carbonatação pela pesagem das amostras e, para uma avaliação mais aprofundada, foi realizado o ensaio de difração de raio-X. Verificou-se que as amostras submetidas à câmara tiveram carbonatação apenas nos primeiros dias. As amostras que ficaram em ambiente laboratorial tiveram comportamento diferente: nos primeiros dias a taxa de carbonatação foi baixa, mas ao longo do experimento, em comparação com as amostras da câmara, apresentaram uma taxa maior de carbonatação. Isto pode ter ocorrido pela rápida carbonatação na superfície, e consequentemente redução dos poros superficiais das amostras que ficaram na câmara, dificultando a penetração de $\mathrm{CO}_{2}$ nos dias subsequentes em camadas mais profundas. Desta forma, foi observado que o ambiente laboratorial apresentou condições mais favoráveis à reação de carbonatação do que a câmara de carbonatação, devido às condições ambientais de temperatura amena em média de $20^{\circ} \mathrm{C}$ e umidade alta (chegando até $80 \%$ ). As condições ambientais da câmara de carbonatação não foram favoráveis para o avanço da carbonatação.
\end{abstract}

Palavras-chave: cal hidratada, carbonatação, argamassas, anidrido carbônico.

\begin{abstract}
Hydrated lime is an air binder widely used in construction, mainly used in mortars for improving rheological behavior. The improvement in the technology of building materials reduced the use of hydrated lime mortars and has been replaced by additives and mineral admixtures, which in most cases confer similar characteristics of mortars in the fresh state but reduced performance in the hardened state. Another important factor which contributes to reduction of its use in mortars refers to the reduced gain strength at early ages, due to slow hardening speed; the solidification depends on the contact with the carbon dioxide from the air. The use of high thicknesses of lime mortar is also a factor in reducing its use because it makes the reaction even slower, affecting the construction schedule. In this context, this article aims to evaluate the potential for carbonation of five different types of hydrated limes found in the Paraná market. To evaluate the carbonation, lime pastes were made and were packed in the laboratory environment and in carbonation chamber with controlled tem-
\end{abstract}


perature and humidity. It became possible to observe the progress of carbonation by weighing of samples and for further evaluation was carried out the diffraction X-Ray analysis. It was found that samples were placed in the chamber weigh gain only during the first days. Samples were left in the laboratory environment at different behavior: at the beginning of the experiment the carbonation rate was low, but at the end, compared with the sample in the chamber, the rate was higher. This may due to the rapid carbonation on the surface, and consequently reducing the surface pores of the samples in the chamber, hindered the penetration of $\mathrm{CO}_{2}$ throughout the experiment in deeper layers. In this way, the laboratorial environmental showed more favorable conditions to the carbonation reaction than carbonation chamber, because of the temperature (average of $20^{\circ} \mathrm{C}$ ) and humidity (up to $80 \%$ ). The progress of the carbonation reaction in the carbonation chamber wasn't favorable because of the aggressive environmental conditions.

Keywords: hydrated lime, carbonation, mortar, carbon dioxide.

\section{INTRODUÇÃO}

A cal hidratada é um importante componente de argamassas utilizadas na construção civil. O seu uso nas argamassas traz vantagens como trabalhabilidade e durabilidade. Porém, há desvantagens, como o seu processo lento de endurecimento e a ausência de requisitos mais efetivos de qualidade das cales na normalização brasileira (a NBR 7175) que determinam uma cal com a qualidade necessária ao seu emprego em argamassas. Atualmente, as argamassas simples de cal hidratada estão sendo usadas para restauração de prédios históricos, pois são produtos compatíveis quimicamente e fisicamente com os materiais tradicionais desses prédios [4].

Um fator importante para a qualidade do produto é o cuidado com a sua produção, que consiste na extração da rocha, calcinação e hidratação. No processo de extração, há diferentes constituições de rochas que poderão ser utilizadas e que irá definir a composição da cal. A diferença na constituição das rochas é a quantidade de cálcio e magnésio presentes, podendo ser calcária $\left(\mathrm{CaCO}_{3}\right)$, dolomítica $\left(\mathrm{CaCO}_{3} \mathrm{MgCO}_{3}\right)$ ou magnesiana (nesse caso com um teor mais elevado de magnésio). Essa rocha é então queimada em fornos de calcinação, com temperaturas entre 700 à $1000^{\circ} \mathrm{C}$ [8] e posteriormente reagem com água, em seu processo de hidratação, formando o produto final da cal, o hidróxido de cálcio e hidróxido de magnésio. Nas argamassas, a cal funciona como um aglomerante aéreo, pois reage com o gás carbônico formando um produto sólido e rígido, processo conhecido como carbonatação.

Há diferentes formulações para as argamassas na construção civil e o que irá definir os materiais e traços será a sua função e aplicação, podendo ser argamassa de assentamento, revestimento de paredes, pisos e tetos, para recuperação de estruturas, entre outras. Nas argamassas mistas, ou seja, de cimento, cal e areia, ocorre dois processos distintos na fase de endurecimento: a hidratação do cimento e a carbonatação da cal. O mecanismo da hidratação do cimento é o fator principal para o endurecimento da argamassa, sendo que o processo de carbonatação influencia a hidratação: altera a cinética convencional de hidratação do clínquer [10]. Já em argamassas simples, de cal e areia, seu endurecimento depende apenas da carbonatação que ocorre lentamente, podendo levar anos para ocorrer.

A reação de carbonatação possui vários fatores intervenientes. MOOREHEAD [9] mostrou alguns destes fatores, tais como: concentração de gás carbônico, temperatura do gás e umidade. Todos os fatores que interferem na taxa de carbonatação da cal são consequência do poder de penetração de $\mathrm{CO}_{2}$ na argamassa. Além desses fatores, a reação depende da presença de água para dissolução e transporte do $\mathrm{CO}_{2}$ ocorrendo rapidamente na superfície externa, sobretudo em uma atmosfera saturada de $\mathrm{CO}_{2}[1,9]$.

A carbonatação da cal, como é chamado seu processo de endurecimento, é a reação de hidróxido de cálcio com o anidrido carbônico, que pode ser descrita pela equação (1) envolvendo um ganho de masssa causado pela transformação do hidróxiodo em carbonato. Esta reação também ocorre com o hidróxido de magnésio, outro constituinte da cal hidratada que funciona como aglomerante.

$$
\mathrm{Ca}(\mathrm{OH}) 2+\mathrm{CO} 2 \longrightarrow \mathrm{CaCO} 3+\mathrm{H} 2 \mathrm{O}+74 \mathrm{KJ}
$$

Este processo é controlado por dois mecanismos principais: difusão do gás atmosférico dentro dos poros da argamassa e reação química entre o $\mathrm{CO}_{2}$ dissolvido e o $\mathrm{Ca}(\mathrm{OH})_{2}$ [2]. Porém, o fato do carbonato ter maior massa e volume que o hidróxido, ao longo do tempo, a argamassa ficará menos permeável, dificultando o mecanismo de difusão do gás carbônico e causando a diminuição da taxa de carbonatação.

DHEILLY et al. [5] estudaram a influência das condições ambientais na taxa de carbonatação de cales. Foi observado que quanto maior a temperatura, menor a taxa de carbonatação, pois há menor absorção de água pela cal e menor solubilidade do gás na água; a temperatura recomendada é de $10^{\circ} \mathrm{C}$, no máximo $20^{\circ} \mathrm{C}$. Em relação à umidade e a porcentagem de $\mathrm{CO}_{2}$, esses pesquisadores observaram uma relação proporcional 
com a taxa de carbonatação; quanto maior a porcentagem destas variáveis, maior a taxa de carbonatação.

Conhecendo-se melhor este fenômeno de endurecimento da cal em argamassas e identificando as melhores condições para a carbonatação, poder-se-á aproveitar o potencial desse fenômeno para obter-se argamassas de cal mais resistentes. Em vista disso, este trabalho objetiva avaliar o potencial de carbonatação de cinco diferentes tipos de cales hidratadas encontradas no mercado paranaense.

\section{MATERIAIS E MÉTODOS}

O programa experimental consistiu no acompanhamento da carbonatação em pastas de cal hidratada por diferença de massa de corpos de prova antes e após exposição em câmara de carbonatação e a partir da análise de DRX pela formação de compostos cristalinos.

\subsection{Materiais}

Para o experimento foram utilizadas cinco diferentes cales hidratadas da região do Paraná, cuja composição química se encontra na Tabela 1.

Tabela 1: Composição química das cales hidratadas, em porcentagem.

\begin{tabular}{l|l|l|l|l|l|l|l|l}
\hline AMOSTRA & $\begin{array}{l}\text { PERDA AO } \\
\text { FOGO (\%) }\end{array}$ & $\mathbf{C O}_{2}(\%)$ & $\begin{array}{l}\text { SÍLICA } \\
+\mathbf{R I}(\%)\end{array}$ & $\mathbf{R}_{2} \mathbf{O}_{3}(\%)$ & $\begin{array}{l}\text { ÓXIDO } \\
\text { DE CÁL- } \\
\text { CIO (F) } \\
(\%)\end{array}$ & $\begin{array}{l}\text { ÓXIDO DE } \\
\text { MAGNÉSIO } \\
(\mathbf{G})(\%)\end{array}$ & $\begin{array}{l}\text { ÓXIDOS } \\
\text { TOTAIS } \\
(\%)\end{array}$ & F/G (\%) \\
\hline $\mathrm{A}$ & 22,6 & 5,0 & 4,0 & 1,0 & 43,2 & 29,6 & 72,8 & 1,46 \\
\hline $\mathrm{B}$ & 24,2 & 4,1 & 2,2 & 1,0 & 43,0 & 29,8 & 72,8 & 1,44 \\
\hline $\mathrm{C}$ & 23,4 & 5,2 & 4,2 & 1,4 & 42,1 & 29,2 & 71,3 & 1,44 \\
\hline $\mathrm{D}$ & 28,8 & 18,5 & 4,2 & 0,6 & 39,6 & 27,0 & 66,6 & 1,47 \\
\hline $\mathrm{E}$ & 24,6 & 9,0 & 5,3 & 0,3 & 41,8 & 28,2 & 70,0 & 1,48 \\
\hline
\end{tabular}

Na composição química das cales quantificou-se a perda ao fogo, presença de $\mathrm{CO}_{2}$, Sílica + RI (resíduos insolúveis), $\mathrm{R}_{2} \mathrm{O}_{3}$ (óxidos livres) e a quantidade de óxidos de cálcio e de magnésio presentes.

Os resultados apresentados demonstram a qualidade das cales. A quantidade de $\mathrm{CO}_{2}$ presente indica se houve correta calcinação da rocha e também se ocorreu alguma carbonatação da cal durante seu armazenamento. $\mathrm{O}$ teor de óxidos totais $(\mathrm{CaO}+\mathrm{MgO})$ indica o poder aglomerante; se for alta a quantidade de óxidos totais, menor será a quantidade de impurezas e maior será seu poder aglomerante. Observa-se que as cales A e B são as que possuem maior poder aglomerante por possuírem as maiores quantidades de óxidos totais. Além disso, podem ser classificadas segundo sua rocha de origem. Pela classificação de GUIMARÃES [7] todas as cales tem como rocha de origem a rocha dolomítica $(\mathrm{CaO} / \mathrm{MgO}$ entre 1,2 e 1,5), origem esperada das cales hidratadas da região do Paraná.

\subsection{Método}

Primeiramente foram feitos os corpos de prova de cales em pasta para a avaliação da carbonatação. Os moldes eram cilíndricos de $2,5 \mathrm{~cm}$ de diâmetro e $1 \mathrm{~cm}$ de altura e foram preenchidos com pastas de cal e água na proporção em massa 1:1.

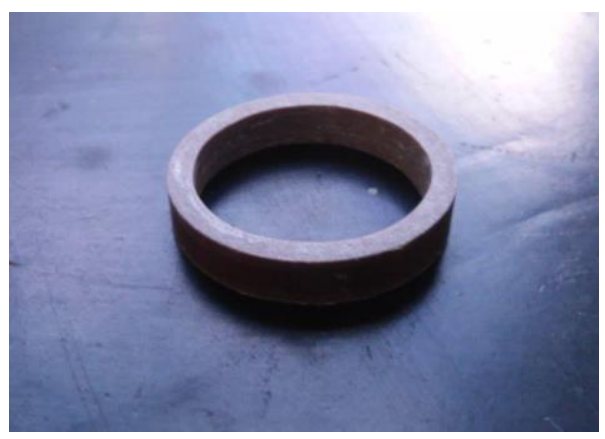

Figura 1: Configuração do molde 
A avaliação da carbonatação foi realizada em duas condições ambientais diferentes: em ambiente laboratorial e em câmara de carbonatação. As condições do ambiente laboratorial (temperatura e umidade) variaram conforme dados de umidade e temperatura apresentados na Figura 2, dentro de valores médios de temperatura e umidade da ordem de $20^{\circ} \mathrm{C}$ e $64 \%$ respectivamente. Essas medições ocorreram diariamente sempre no mesmo horário.

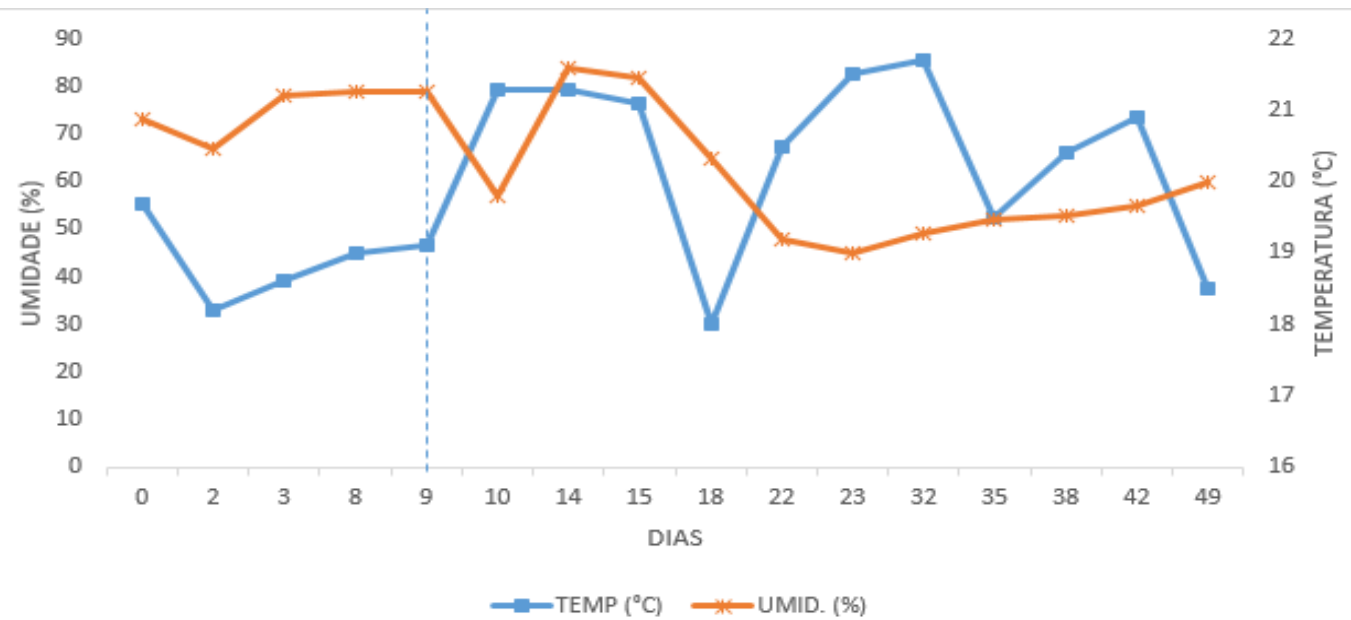

Figura 2: Condições ambientais do laboratório

As condições na câmara de carbonatação foram as seguintes: umidade de $60 \%$, temperatura de $40^{\circ} \mathrm{C}$ e taxa de $\mathrm{CO}_{2}$ de $4,2 \%$. Estas condições foram impostas às amostras, pois foi utilizada uma câmara de carbonatação da marca Bass Equipamentos, modelo UUC-RH-STD-CO2-1000/2013 que estava em fase de implantação, por isso, não houve condições de ajuste das variáveis em tempo para o presente experimento.

Em ambos os ambientes, três corpos de prova de cada cal hidratada foram pesados semanalmente, porém os tempos de experimento se diferenciaram. Em ambiente laboratorial o experimento se prolongou durante 49 dias; na câmara de carbonatação, o experimento ocorreu durante 28 dias. O tempo de exposição dos corpos de prova na câmara foi mais curto, pois como é um processo acelerado, as amostras mostraram constância de peso mais rapidamente. Com isso, pôde-se observar o ganho de massa das cales devido à transformação do hidróxido em carbonato.

Além da pesagem dos CP's foi realizado o ensaio de difração de raio-X (DRX). Este ensaio auxiliou na identificação qualitativa dos minerais constituintes das pastas de cal antes do processo de carbonatação e após esse processo. As espécies químicas cristalinas, a partir da interação de raios-X incidentes, resultam em raios-X difratados característicos para cada ângulo de incidência [1]. Para este estudo, foram também obtidos resultados semi-quantitativos a partir do ensaio de DRX, mostrando de forma aproximada a quantidade dos minerais identificados nas amostras.

\section{RESULTADOS E DISCUSSÕES}

\subsection{Ganho de massa das amostras expostas à carbonatação}

Os gráficos das Figuras 3 e 4 mostram o ganho de massa, em percentual, das amostras de pastas de cal, após a ocorrência do processo de carbonatação em ambiente laboratorial e também após exposição em câmara de carbonatação. Como foram pesados três CP's de cada cal hidratada, os gráficos mostram a média dos resultados obtidos considerando-se exclusão de valores espúrios. Os ganhos de massa observados dos três CP's de cada amostra de cal foram semelhantes, sendo o maior desvio padrão obtido igual à 0,46 no ambiente laboratorial e igual à 0,58 na câmara de carbonatação.

Analisando-se os gráficos das Figuras 3 e 4, pode-se notar a principal diferença no comportamento do ganho de massa entre os dois ambientes. As amostras que ficaram em ambiente laboratorial obtiveram ganho de massa gradativo ao longo do experimento e a sua estabilização ocorreu após o $22^{\circ}$ dia de experimento. Diferentemente, as amostras expostas à câmara de carbonatação apresentaram significativo ganho de massa até o $4^{\circ}$ dia e logo atingiram a estabilização. 


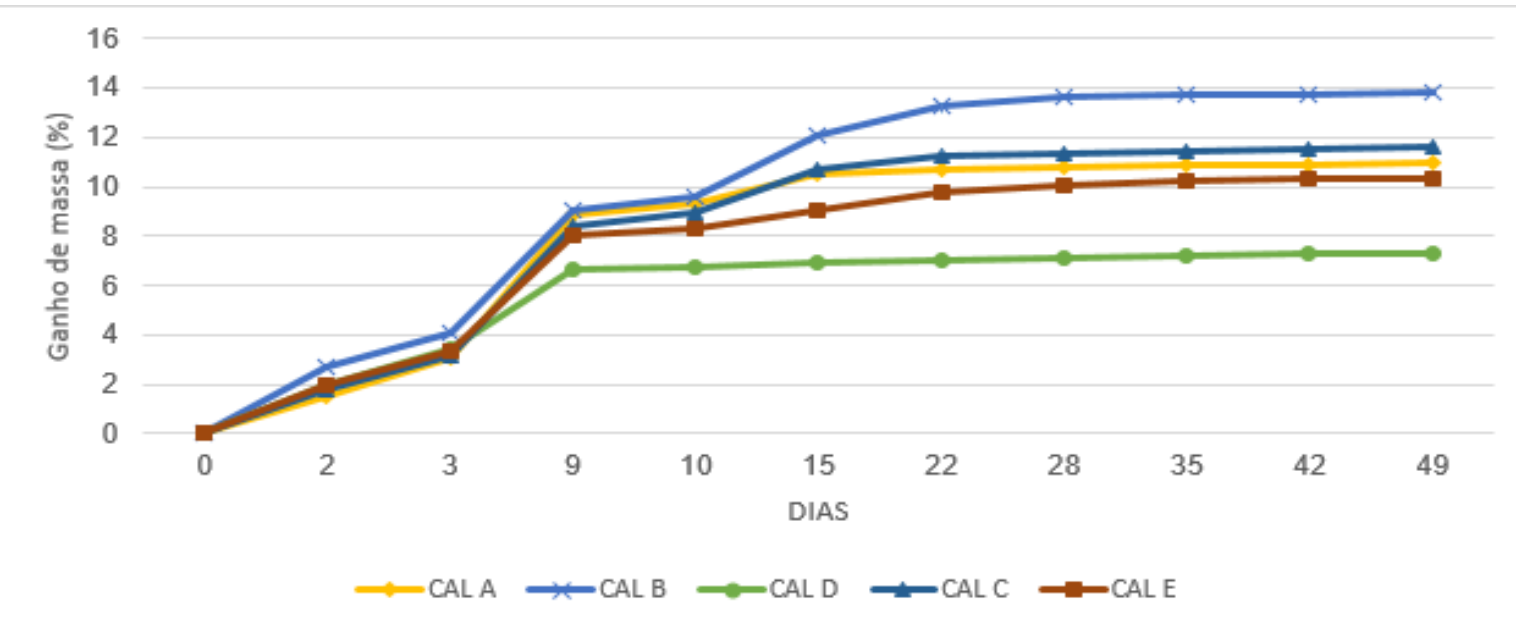

Figura 3: Percentual de ganho de massa das amostras de cal hidratada submetidas ao ambiente laboratorial

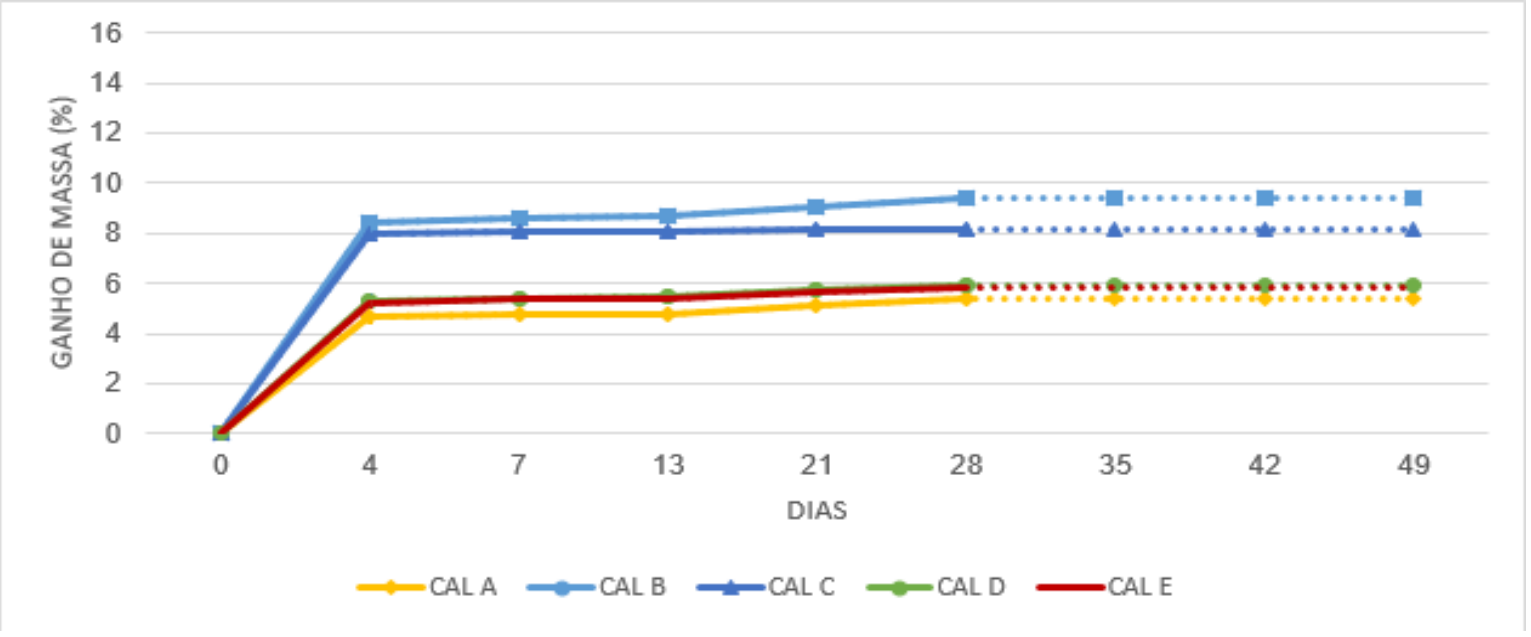

Figura 4: Percentual de ganho de massa das amostras de cal hidratada submetidas à câmara de carbonatação

Obs: as linhas horizontais pontilhadas indicam a previsão de comportamento a partir de 28 dias.

Na Figura 4, os dados a partir do $28^{\circ}$ dia, marcados com linha tracejada, foram estimados, tendo em vista a ocorrência de uma estagnação dos ganhos de massa. Essa estagnação pode ter ocorrido devido à alta taxa de $\mathrm{CO}_{2}$ no ambiente interno da câmara. A reação deve ter ocorrido na superfície das amostras nos primeiros dias, tornando-as menos permeáveis, dificultando com isso a evolução da penetração de $\mathrm{CO}_{2}$ para o interior da amostra. Outra hipótese para este comportamento é a elevada temperatura no interior da câmara. Esta temperatura pode ter interferido na taxa de carbonatação, devido provavelmente a evaporação da água no interior do corpo de prova. Ou seja, a temperatura elevada pode ter diminuído a umidade no interior da amostra, condição fundamental para o processo de carbonatação.

Observando os gráficos das Figuras 2 e 3 em conjunto, observa-se uma relação do ganho de massa com as condições ambientais do laboratório, confirmando a influência da temperatura e umidade neste processo de carbonatação. Do início do experimento até o $9^{\circ}$ dia, as amostras apresentaram significativo ganho de massa e nesse mesmo período a umidade do laboratório estava alta e a temperatura não ultrapassou $20^{\circ} \mathrm{C}$ (temperatura recomendada por DHEILLY et al. [5]). Após este período, o ganho de massa foi pequeno e as condições ambientais foram contrárias ao início do experimento; a umidade ficou baixa e a temperatura foi maior que $20^{\circ} \mathrm{C}$, ou seja, a água disponível no interior da amostra para a reação foi consumida pela temperatura, estagnando a reação de carbonatação.

Nos gráficos das Figuras 3 e 4, também nota-se o seguinte: as cales que apresentaram maior ganho de 
massa no ambiente laboratorial foram as mesmas que tiveram maior ganho de massa na câmara de carbonatação.

Outro comportamento relevante é a coerência no ganho de massa das cales com sua composição química apresentadas pelas mesmas (Tabela 1). As cales que possuem maior teor de óxidos totais são as que tiveram maior ganho de massa, pois há maior teor de partículas reagentes (óxidos totais), logo este comportamento foi observado em ambos os ambientes, em maior ou menor taxa em função das condições ambientais. Porém, a cal A teve um comportamento inesperado. Por apresentar um alto teor de óxidos totais, esperava-se da cal A um elevado ganho de massa, mas na câmara de carbonatação, seu ganho de massa foi menor que as cales que possuem teor de óxidos totais inferior a esta. Este comportamento inesperado pode ter ocorrido provavelmente devido à um problema não identificado durante o experimento, portanto sujeito a reavaliação.

\subsection{Análises realizadas com a DRX}

A seguir estão os difratogramas que foram obtidos a partir do ensaio de DRX das amostras que foram submetidas às condições do ambiente laboratorial (Figura 6), dados qualitativos, e a tabela dos dados semiquantitativos das mesmas amostras (Tabela 2). Os difratogramas foram obtidos a partir das amostras de pasta de cal que ficaram no ambiente do laboratório durante 7 dias e 49 dias.

Figura 5: Difratograma de todas as cales

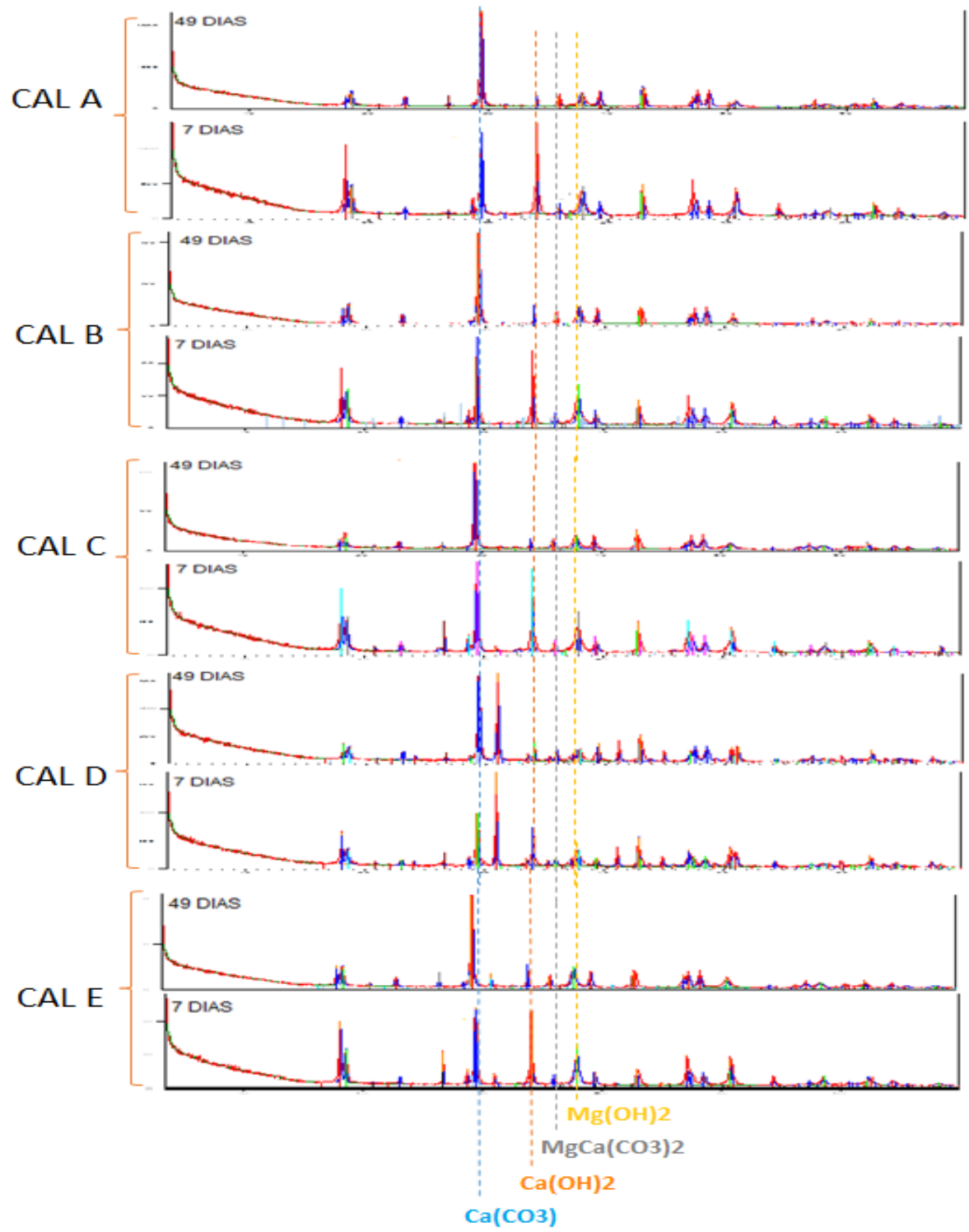


Tabela 2: Resultados semi-quantitativos do ensaio de DRX

\begin{tabular}{|c|c|c|c|c|c|c|c|c|c|c|}
\hline & \multicolumn{2}{|c|}{ CAL A } & \multicolumn{2}{|c|}{ CAL B } & \multicolumn{2}{|c|}{ CAL C } & \multicolumn{2}{|c|}{ CAL D } & \multicolumn{2}{|c|}{ CAL E } \\
\hline & $\begin{array}{l}7 \\
\text { DIAS } \\
(\%)\end{array}$ & $\begin{array}{l}9{ }^{4} \\
9 \text { DIAS } \\
(\%)\end{array}$ & $\begin{array}{l}\text { DIAS } \\
\text { (\%) }\end{array}$ & $\begin{array}{l}{ }^{4} \\
9 \text { DIAS } \\
(\%)\end{array}$ & $\begin{array}{l}{ }^{7} \\
\text { DIAS } \\
(\%)\end{array}$ & $\begin{array}{l}9{ }^{4} \\
9 \text { DIAS } \\
(\%)\end{array}$ & $\begin{array}{l}{ }^{7} \\
\text { DIAS } \\
(\%)\end{array}$ & $\begin{array}{l}9 \\
9 \text { DIAS } \\
(\%)\end{array}$ & $\begin{array}{l}{ }^{7} \\
\text { DIAS } \\
(\%)\end{array}$ & $\begin{array}{l}9 \\
9 \text { DIAS } \\
(\%)\end{array}$ \\
\hline $\mathrm{CaCO}_{3}$ & 34 & 66 & 37 & 63 & 33 & 69 & 23 & 34 & 33 & 53 \\
\hline $\mathrm{Ca}(\mathrm{OH})_{2}$ & 35 & 7 & 29 & 12 & 28 & 9 & 16 & 8 & 29 & 12 \\
\hline $\mathrm{Mg}(\mathrm{OH})_{2}$ & 20 & 13 & 24 & 18 & 22 & 17 & 10 & 7 & 26 & 17 \\
\hline
\end{tabular}

A partir da análise dos resultados do ensaio de DRX, todas as cales apresentaram um comportamento semelhante. Observa-se que os picos de hidróxido de cálcio são maiores nos difratogramas de 7 dias. Este resultado tem coerência com os resultados das pesagens dos corpos de prova, pois mostra que houve a reação do $\mathrm{Ca}(\mathrm{OH})_{2}$ com o $\mathrm{CO}_{2}$, formando o $\mathrm{CaCO}_{3}$. Além da reação com o hidróxido de cálcio o gás carbônico também reagiu com o hidróxido de magnésio. Estes comportamentos também puderam ser observados nos resultados semi-quantitativos do ensaio de DRX.

Os resultados semi-quantitativos estão relacionados com os difratogramas, mostrando, novamente, a reação do $\mathrm{CO}_{2}$ com os hidróxidos presentes nas amostras de todas as cales observadas. Isso é mostrado no resultado pelo teor de $\mathrm{Ca}(\mathrm{OH})_{2}$, que foi maior nas amostras de 7 dias, e pelo teor de $\mathrm{CaCO}_{3}$, que foi maior nas amostras de 49 dias. Porém, o resultado semi-quantitativo mostrou falhas, pois não indicou a presença de carbonato de magnésio, como indica os resultados qualitativos. Talvez pelo baixo teor de óxidos de magnésio nas amostras quando comparados aos teores de óxidos de cálcio, ou devido à alguma particularidade química desse elemento relativa ao desempenho na carbonatação, não avaliado nesse trabalho.

\section{CONCLUSÕES}

Devido aos ensaios realizados para a verificação do processo de carbonatação foi possível observar que a carbonatação da cal é sensível aos fatores externos do ambiente em que a mesma está inserida, além de sua composição química e condições climáticas internas que alteram o comportamento da carbonatação. Pode-se notar a diferença da taxa de carbonatação nos diferentes ambientes externos: laboratorial e câmara de carbonatação; isso se deve as diferentes condições ambientais impostas em cada um.

$\mathrm{O}$ ambiente laboratorial, que apresentou temperatura amena $\left(20^{\circ} \mathrm{C}\right)$ e umidade alta (chegando até 80\%), apresentou condições mais favoráveis à reação de carbonatação, como indicado por DHEILLY et al. [5], pois houve um aumento expressivo no ganho de massa das pastas de cal. Já as condições da câmara de carbonatação, temperatura elevada $\left(40^{\circ} \mathrm{C}\right)$ e alta taxa de $\mathrm{CO}_{2}$, mostraram-se agressivas, o que pode ter impedido a evolução da carbonatação nas pastas, devido a reduzida disponibilidade de umidade no interior da amostra e à colmatação dos poros superficiais provocada pela acelerada exposição ao $\mathrm{CO}_{2}$.

Além das condições ambientais, outro fator que indicou diferença com a taxa de carbonatação foi a composição química da cal hidratada. Os resultados de composição química mostram coerência com os resultados de ganho de massa e DRX, pois as cales que apresentaram maior teor de material aglomerante, foram as mesmas que apresentaram maior ganho de massa. Nota-se também a diferença na carbonatação dos óxidos de cálcio e dos óxidos de magnésio. Apesar do óxido de magnésio também ser um reagente da carbonatação, as pastas de cales que possuíam alto teor deste óxido, não apresentaram grande ganho de massa, como as pastas de cales que possuíam alto teor de óxido de cálcio. Uma investigação mais detalhada sobre essa diferença deverá ser aprofundada.

Os ensaios realizados neste trabalho, ganho de massa e DRX, apresentaram boa coerência para a avaliação da carbonatação. Além dos resultados qualitativos do DRX, o ensaio semi-quantitativo obtido a partir do ensaio de difração, mostrou-se apropriado para a avaliação realizada, dando melhores subsídios para a análise do impacto da carbonatação nas amostras de cal hidratada.

\section{AGRADECIMENTOS}

Ao Laboratório de Análises de Minerais e Rochas (LAMIR/UFPR) pelas análises de DRX, ao Laboratório de Tecnologia de Argamassas (LATECA/UFPR) pela infra-estrutura de apoio à pesquisa e ao CNPq pelo apoio financeiro. 


\section{BIBLIOGRAFIA}

[1] BALEN, R. T. V., GERMERT, D. V., “Modelling lime mortar carbonation”, Mater struct, v. 27, pp. 393 398, jan. 1994.

[2] CIZER, O., BALEN, K. V., ELSEN, J., GEMERT, D.V., "Real-time investigation of reaction rate and mineral phase modifications of lime carbonation", Construction and building materials, v. 35, pp. 741-751, oct. 2012.

[3] COSTA, M. R. M. M., Análise comparativa de argamassas colantes de mercado através de parâmetros reológicos. Tese de D.Sc., EPUSP, São Paulo, SP, Brasil, 2007.

[4] CULTRONE, G., SEBASTIÁN, E., HUERTAS, M. O., "Forced and natural carbonation of lime-based mortars with and without additives: Mineralogical and textures changes", Cement and concrete research, v. 35, pp. 2278-2289, dec. 2005.

[5] DHEILLY, R. M., TUDO, J., BI, Y. S., QUÉNEUDEC, M., "Influence of storage conditions on the carbonation of powdered $\mathrm{Ca}(\mathrm{OH})_{2}$ ", Construction and building materials, v. 16, pp. 155-161, jan. 2002.

[6] EL-TURKI, A., BALL, R. J., ALLEN, G. C., "The influence of relative humidity on structural and chemical changes during carbonation of hydraulic lime", Cement and concrete research, v. 37, pp. 1233-1240, may. 2007.

[7] GUIMARÃES, J. E. P., A cal: Fundamentos e aplicações na engenharia civil, 2 ed., São Paulo, Pini, 2002.

[8] MATTANA, A. J., Estudos de cales hidratadas de mercado - caracterização química, física e comportamento reológico da pasta, Tese de M.Sc., PPGECC/UFPR, Curitiba, PR, Brasil, 2013.

[9] MOOREHEAD, D.R., "Cementation by the carbonation of hydrated lime", Cement and concrete research, v. 16, pp. 700-708, jun. 1986.

[10] QUARCIONI, V. A., A influência da cal hidratada nas idades iniciais da hidratação do cimento Portland-estudos em pasta. Tese de D.Sc., EPUSP, São Paulo, SP, Brasil, 2008. 